\title{
The Specialty Board Movement at the Crossroads: Reaction to the Paper by Kevin B. Weiss, MD
}

Janet M. Corrigan, $P h D, M B A$

Dr. Weiss ${ }^{1}$ has provided an excellent overview of the evolution of certification boards and the many environmental forces that will shape their future. I concur that boards are indeed at a crossroads-they can continue to function primarily as professional, self-regulatory bodies or they can embrace a broader public accountability model. But should the boards continue to pursue the status quo, they will probably become less relevant over time. They will also have passed up an opportunity to play a key role in solving our nation's health care challenges.

The health care sector is confronting serious challenges: quality gaps, safety concerns, unsustainable costs, and health care disparities. Addressing these challenges will require fundamental reform of the delivery system, including the development of clinically integrated systems that use interdisciplinary teams to provide patient-centered care. These systems of care must be capable of achieving the best outcomes and providing affordable care to the populations served.

Calls for greater public accountability have been intensifying for over 2 decades and show no signs of abating. There is now a robust "quality enterprise" consisting of various public- and private-sector organizations and alliances working together to establish national priorities and goals for transforming health care; to develop and endorse standardized measures of quality and cost; to publicly report performance results; to align payment programs; and to make knowledge and tools available to assist with system redesign and performance improvement. To date, certification boards have played a minimal role; they have neither a strong voice nor a well-defined space on the quality landscape.

From the National Quality Forum, Washington, D.C.

Funding: none.

Conflict of interest: none declared.

Corresponding author: Janet M. Corrigan, PhD, MBA, National Quality Forum, Suite 500 North, 601 Thirteenth Street NW, Washington, DC 20005 (E-mail: corrigan@qualityforum.org).
Certification boards represent an untapped resource. This is not meant to minimize the many important contributions that boards have made to improving quality. It is just that the current environment presents enormous opportunities for the boards to have a far greater impact by collaborating and aligning their activities with those of the broader quality enterprise.

Some of the steps boards now could take to contribute to the achievement of the national quality agenda include:

1. Providing strong, coordinated leadership. The health care system is changing at a rapid pace and physicians need help adapting. Certification boards, working collaboratively with medical societies and others, have an opportunity to develop a "common agenda" in the following areas:

- Evidence-based guidelines

- Performance measures and clinical decision support for use with electronic health records

- Registries and other data sources

- Knowledge and tools for redesigning care processes and quality improvement

2. Strengthen core competencies in emerging areas. Physicians rapidly need to acquire knowledge and skills in new areas to assume leadership responsibilities and thrive in the evolving health care system. For example, maintenance of certification could play a greater role in helping physicians acquire knowledge and skills in the following areas:

- Patient-centered care (methods of engaging patients through use of shared decision making tools and cultural competency training)

- Systems-based care delivery (characteristics of high-performing health care systems, continuous quality improvement tools and applications, and effective use of health information technology) 
- Appropriateness and waste (reinforce responsibility of medical professionals to serve as stewards of scarce resources and enhance understanding of unexplained variability in practice, effects of fee-for-service payment on volume of services, and opportunities to reduce waste)

3. Define position on quality landscape and harmonize with others. Boards should continue to align their programs with the national priorities and goals established by the National Priorities Partnership; use measures endorsed by the National Quality Forum whenever possible; coordinate measure development activities with medical societies and others; and consider an expanded role in public reporting.

In summary, the certification boards have an extraordinary opportunity to amplify their impact and to play a critical role in addressing some of the health system's most pressing problems. Boards will need to strike the right balance between professional self-regulation and accountability. They are not mutually exclusive, but there are inherent tensions. Boards will also need to develop stronger relationships with others involved with enhancing physician performance through public reporting and payment reform to assure that their activities are complementary and mutually reinforcing. Lastly, as systems-based care evolves, boards will need to actively participate in efforts to redefine physician responsibility and accountability within a broader framework that recognizes communitylevel partnerships, accountable care organizations, and interdisciplinary teams.

\section{Reference}

1. Weiss KB. Future of board certification in a new era of public accountability. J Am Board Fam Med 2010; 23(Suppl):S32-9. 